\title{
Segregation through Conflict
}

\author{
Salam Md. Mahbubush Khan ${ }^{1}$, Kazuyuki Ikko Takahashi ${ }^{2}$ \\ ${ }^{1}$ Department of Mathematics, Alabama A\&M University, Normal, USA \\ ${ }^{2}$ School of Political Economy, Meiji University, Tokyo, Japan \\ Email: salam.khan@aamu.edu, ikko@kisc.meiji.ac.jp
}

Received October $3^{\text {rd }}, 2013$; revised November $3^{\text {rd }}, 2013$; accepted November $10^{\text {th }}, 2013$

\begin{abstract}
Copyright $(2013$ Salam Md. Mahbubush Khan, Kazuyuki Ikko Takahashi. This is an open access article distributed under the Creative Commons Attribution License, which permits unrestricted use, distribution, and reproduction in any medium, provided the original work is properly cited.
\end{abstract}

\begin{abstract}
This paper begins by introducing the game theory to explain how an institution emerges. It then goes on to employ a conflict model, using the probability distribution introduced by Koshmanenko, to show how institutions emerge through mathematical formation. This is followed by a consideration of the authors' development of a segregation simulation based on this conflict theory. An institution is defined as the equilibrium achieved through the segregation of conflicting groups (for example groups differing according to "race", or language, education or income level among other factors). A simulation is made explaining how equilibrium is reached through changing probability. This simulation also shows the dynamics of an emerging new order.
\end{abstract}

Keywords: Game Theory; Conflict; Segregation; Social Convention; Probability Distribution

\section{Introduction}

There are several arguments showing how a social convention is established. One defines it as how the rules of a game evolve through being repeatedly played (Aoki, 2000, 2001: Chap.1). When the result of the game reaches equilibrium, an institution is thought to emerge. This study analyzes this theory and extends it to the conflict theory, which is proposed later. The authors aim to explain the emergence of social conventions through this conflict theory.

David Hume is prominent among political thinkers for his explanation of the origins of the institution (Hume, 2000). Both he and Adam Smith discussed the mechanism of the generation of an institution through conflict between individuals (Smith, 1976). In Hume's theory, the institution emerges from convention. "This (establishing the institution of property) can be done after no other manner, than by a convention entered into by all the members of the society to bestow stability on the possession of those external goods, and leave everyone in the peaceable enjoyment of what he may acquire by his fortune and industry" (Hume, 2000: Book 3 Part 2 Section 2). The following convention is exactly the same: "Two men, who pull the oars of a boat, do it by an agreement or convention, though they have never given promises to each other" (ibid). Thus two conflicting people reach the convention; and, if here, there is a large boat with many oars, all members of the crew who are in conflict with each other pull them by convention. An explanation of this mechanism is given using game theory, and then the authors introduce their model to further elucidate.

\section{Game Theory and the Emergence of Institutions}

The simplest form of the game theory is the dyad one-shot game, which deals with two persons each able to make rational choices. It should be noted that one of the authors has previ- ously argued Hobbes' contract theory using this type of game theory (note: self reference). There are two strategies, one of which is to cooperate to make a social contract $(A)$, whilst the other is to continue the condition of war $(B)$. These strategies lead to the matrix of one person:

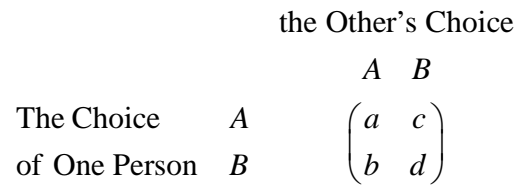

The other's matrix is supposed to be the same. In the chicken game, for instance, the two players feel a dilemma because the strategy of deceit may be attractive $(b>a)$, but finally both of them could choose the strategy of cooperation $(a>c>d)$, and then, they could reach agreement. That is Nash equilibrium ( $A$, $A)$. Nash equilibrium requires that not only should a strategy be optimal according to what one player believes the other player's strategy is, it should be optimal based upon the first player also considering this the right strategy (Weibull, 1995). This whole process corresponds with Hobbes' social contract theory (Hobbes, 1968).

This chapter briefly deals with repeated game theory. It also considers the population game as an extension of this game of individuals' strategy; this is in order to explain the mechanism of institution as deriving from the endogenous rules of the game (as for the relationship between dyad-one-shot game, dyad-repeated game and population game, see Morrow, 1994, Weibull, 1995, Matsui, 1996, Young, 1998, Gintis, 2000). In Hume's example, the game of "Two men, who pull the oars of a boat" corresponds to the repeated dyad game. The matrix is exactly the same as the above example of the dyad one-shot game. In the game of one-shot, the most reasonable preference is not easily determined. In the chicken game, Nash equilibrium 
is $(A, A)$, which is above shown, but in the prisoner's dilemma, it is $(B, B)$. In the repeated game, however, it is intuitively and logically easy to obtain. That is, Nash equilibrium $(A, A)$ is easily determined even in the prisoner's dilemma.

This paper builds on Hume's example by using that of a large boat with many members of crew. That is not a dyad (one to one) game, but a one to many game: this results in matrix (2). A person should choose the best preference through predicting the others' preferences. The authors' difficulty in choosing the manner of rowing forced them to look for a clearer and more understandable example of an emerging institution.

Suppose that one rides an escalator. A person may stand passively or actively walk up the ascending stairs. When the escalator has two lines, the protagonist has two strategies. One is that if a person wants to stand passively, he chooses the right line and if he walks, he uses the left line. That is strategy $A$. Strategy $B$ is the opposite: one stands on the left line or walks up on the right.

When everyone chooses a strategy, it becomes a social convention, or an institution. Thus, if it can be explained how a strategy is chosen by many people, then it can be shown how an institution emerges. UUT

$$
\begin{aligned}
& \text { the Others' Choices } \\
& \text { A } B \\
& \begin{array}{ll}
\text { The Choice } & A \\
\text { of One Person } & B
\end{array} \quad\left(\begin{array}{ll}
a & c \\
b & d
\end{array}\right)
\end{aligned}
$$

The above example is a population game with a pay-off matrix. It is not a dyad, but a one to many game. This formula is similar to the iterated game, in which rational players are fixed. However in the population game each player meets one another randomly. Pay-off is calculated through strategy distribution. It is a situation where the probability of people choosing the strategy is determined at the stage of $t$. More strictly, it is as follows:

$$
\left(\begin{array}{l}
A t \\
B t
\end{array}\right)=\left(\begin{array}{ll}
a & c \\
b & d
\end{array}\right)\left(\begin{array}{c}
x t \\
1-x t
\end{array}\right)=\left(\begin{array}{l}
a x t+c(1-x t) \\
b x+d(1-x t)
\end{array}\right) ; t=0,1,2, \cdots
$$

There is a population. What percentage of it chooses a strategy is determined. In this, the games are repeated through the discrete stages, $t=0,1,2, \cdots$ and $x t$ is the probability of choosing the strategy $A$, and $(1-x t)$ is the strategy $B$ 's. Therefore, $(A t, B t)$ is the matrix of pay-off at time $t$.

Here, if $A_{0}$ is larger than $B_{0}, A^{\infty}=1$, and $B^{\infty}=0$. The matrix is mathematically calculated; but here its meaning should be explained. For an intuitive understanding, it can be reckoned that when the choice of one person is the same as the others' choice, the pay-off is 1 , and if not, it is 0 :

$$
\left(\begin{array}{ll}
a & c \\
b & d
\end{array}\right)=\left(\begin{array}{ll}
1 & 0 \\
0 & 1
\end{array}\right)
$$

From this the following equation is reached:

$$
\left(\begin{array}{l}
A t \\
B t
\end{array}\right)=\left(\begin{array}{ll}
1 & 0 \\
0 & 1
\end{array}\right)\left(\begin{array}{c}
x t \\
1-x t
\end{array}\right)=\left(\begin{array}{c}
x t \\
1-x t
\end{array}\right) ; t=0,1,2, \cdots
$$

All the people in this game may not change their strategies all at once, but only gradually. In each stage, each player normalizes a given strategy distribution and chooses his strategy. Thus the following equation can be arrived at:

$$
\left(\begin{array}{l}
A t \\
B t
\end{array}\right):\left(\begin{array}{c}
x_{0} \\
1-x_{0}
\end{array}\right),\left(\begin{array}{c}
x_{1} \\
1-x_{1}
\end{array}\right),\left(\begin{array}{c}
x_{2} \\
1-x_{2}
\end{array}\right), \cdots
$$

Not all players would switch simultaneously to the best strategy, but gradually switch over time for two reasons: inertia and myopia (Aoki, 2001: Chap.5). Inertia results from the costs of changing strategies, whilst myopia means that they search for strategies within limited horizons.

Consequently these time series would converge to an "institution". According to Aoki, an institution is a self-assuming system of shared beliefs about how the game is played (Aoki, 2001: p. 185). That result would be $(1,0)$, or $(0,1)$.

There are two institutions, $A$ or $B$. Which institution should be chosen is contingent, but it depends on the initial condition. This characteristic is called path dependence. There is another notion, which depends on mutation or noise (see Kandori et al., 1993, Young, 1993), but this is not considered here.

\section{Game Theory to the Conflict Model}

The evolutionary game theory can be extended to the conflict model, as it may also be adapted to the change from the coordination game to a conflict game. This idea is based upon the Koshmanenko model (Koshmanenko, 2003, 2004).

Koshmanenko develops mathematical tools suitable for the construction of conflict models with two non-annihilating adversaries. His model deals with the distribution of probabilities of two groups. This probability distribution changes its value over time.

He proposes some equations of stochastic vectors $\boldsymbol{P}$ and $\boldsymbol{Q}$, which are used in this paper, and proves that the limiting vectors are $(0,1),(1,0)$ or $(1 / 2,1 / 2)$.

From this, the meaning of the conflict can be understood. When one rides an escalator, one stands passively or actively walks up the ascending stairs. An individual can make four choices: stand passively or walk up, on the right or the left line.

In the conflict situations, there are two attributes, one of which is changeable and the other is not. The changeable is represented as columns and the unchangeable as rows. Conflict occurs in the same row between different columns, or in the same column between different rows. In both cases, conflicting elements would change their columns, thus conflicts would diminish and then disappear.

Here this model is not thought of as an individual's choices, but the interrelation of groups of indistinguishable members. Thus, the authors suppose that there are four groups, each of which selects one of those four choices. The game theory mentioned above depends on cooperation, but here the theory depends on conflict. The difference is that the former is determined by an individual's choice and the latter by probability distribution.

The elements of the following matrix represent those four choices as probability. One case is that there are two rows, $\left(p_{1}, p_{2}\right)$ as the right side and $\left(q_{1}, q_{2}\right)$ as the left. There are also two columns, $\omega_{1}$ as standing and $\omega_{2}$ as going up.

Case 1

$$
\begin{aligned}
& \omega_{1} \omega_{2} \\
& \text { stand go up } \\
& \text { right } \quad\left(\begin{array}{ll}
p_{1} & p_{2} \\
q_{1} & q_{2}
\end{array}\right) \\
& p_{1}+p_{2}=1 \quad q_{1}+q_{2}=1
\end{aligned}
$$


People cannot change the lines, but only the behavior. It is supposed that the number of the people who are in the right line and the left are the same.

Or case 2

$$
\begin{aligned}
& \omega_{1} \omega_{2} \\
& \text { right left } \\
& \text { gtand }\left(\begin{array}{ll}
p_{1} & p_{2} \\
q_{1} & q_{2}
\end{array}\right) \\
& p_{1}+p_{2}=1 \\
& q_{1}+q_{2}=1
\end{aligned}
$$

People do not change the behavior, but change the lines.

The authors consider the latter case (case 2) more realistic. In this model, people change the lines after seeing the behaviors of those people who are in the same line.

It must be emphasized that the limiting distribution of the matrix strongly depends on the initial conditions. Koshmanenko shows such phenomena in a purely mathematical way for two opponents (Koshmanenko, 2003, 2004). However in the next section they are demonstrated through a generalized simulation so that more complicated situations may be dealt with. Moreover by assuming an initial distribution, the result is obtained by purely mathematical means.

Here the meaning of conflict becomes clear. Those two groups of people who are in the same line, but have different behavior cannot remain in the same line as conflict would inevitably occur; and moving out and moving in would necessarily follow.

\section{Conflict Theory to Our Segregation Model}

Now the segregation model is finally proposed. Here the interrelation between groups is also supposed. Unlike Schelling's model, the individual's choice is not supposed. As is well known, Schelling uses a checkerboard to demonstrate how a city comprising agents of different "races", initially highly diversified, might change into a segregated city (Schelling, 1969). The Schelling model explains how individual movements change the social order. The essence of his argument is that microscopic motions could change the macro order drastically. However, here the authors' model analyzes the semi-macroscopic change from the beginning. Thus the change from evolutionary game theory to conflict model is paralleled by the change from the Schelling model to the segregation model.

This is also an extension of Koshmanenko's conflict model and shares its example of non-annihilating conflict.

Suppose that we have a $2 \times 2$ matrix.

$$
\left(\begin{array}{ll}
p_{1} & p_{2} \\
q_{1} & q_{2}
\end{array}\right)
$$

There is conflict between $\left(p_{1}, p_{2}\right)$ and $\left(q_{1}, q_{2}\right)$. When the elements are understood to be groups of indistinguishable individuals it can be noticed that there is conflict between $p_{1}$ and $q_{1}$, and attraction between $p_{1}$ and $p_{2}$.

So the progression can be seen, from the use of the escalator model, and then the conflict model to finally reaching the segregation model.

One of the merits of our model is that it easily creates simulation; its results are shown in the next section.

The study then proceeds to the mathematical formulation. In order to simplify the explanation the formulation of the model is restricted to $2 \times 2$.

Denote two positions using $\omega_{1}, \omega_{2}$ and put $\Omega=\left\{\omega_{1}, \omega_{2}\right\}$, that can be occupied by each of two opponents $A_{1}$ and $A_{2}$.

Suppose that each of $A_{1}$ and $A_{2}$ has an initial probability distribution to occupy the position $\omega_{1}, \omega_{2}$ at time 0 . The assumption is that:

$$
\begin{aligned}
& p_{1}^{(0)}+p_{2}^{(0)}=1 \\
& q_{1}^{(0)}+q_{2}^{(0)}=1
\end{aligned}
$$

Then, the conflict of each opponent for each position is defined as follows:

$$
\begin{aligned}
& p_{i}^{(1)}:=\frac{1}{z^{(0)}} p_{i}^{(0)}\left(1-q_{i}^{(0)}\right) ; i=1,2 \\
& q_{i}^{(1)}:=\frac{1}{z^{(0)}} q_{i}^{(0)}\left(1-p_{i}^{(0)}\right) ; i=1,2
\end{aligned}
$$

Where the normalizing coefficient is;

$$
z_{1}^{(0)}=1-p_{1}^{(0)} q_{1}^{(0)}-p_{2}^{(0)} q_{2}^{(0)}
$$

The probability distributions change in the following way:

$$
\left(\begin{array}{ll}
p_{1}^{(0)} & p_{2}^{(0)} \\
q_{1}^{(0)} & q_{2}^{(0)}
\end{array}\right) \rightarrow\left(\begin{array}{ll}
p_{1}^{(1)} & p_{2}^{(1)} \\
q_{1}^{(1)} & q_{2}^{(1)}
\end{array}\right)
$$

In the same way, the elements of the probability distribution after $k$-th conflict can be defined as follows:

$$
\begin{aligned}
& p_{i}^{(k)}:=\frac{1}{z^{(k-1)}} p_{i}^{(k-1)}\left(1-q_{i}^{(k-1)}\right) ; i=1,2 \\
& q_{i}^{(k)}:=\frac{1}{z^{(k-1)}} q_{i}^{(k-1)}\left(1-p_{i}^{(k-1)}\right) ; i=1,2
\end{aligned}
$$

where the normalizing coefficient is:

$$
z^{(k-1)}=1-p_{1}^{(k-1)} q_{1}^{(k-1)}-p_{2}^{(k-1)} q_{2}^{(k-1)}
$$

The probability distributions change in the following manner:

$$
\left(\begin{array}{ll}
p_{1}^{(k-1)} & p_{2}^{(k-1)} \\
q_{1}^{(k-1)} & q_{2}^{(k-1)}
\end{array}\right) \rightarrow\left(\begin{array}{cc}
p_{1}^{(k)} & p_{2}^{(k)} \\
q_{1}^{(k)} & q_{2}^{(k)}
\end{array}\right)
$$

This $2 \times 2$ matrix can be extended to $m \times n$. One of the authors has already formulated the general situation of conflict between multi-opponents (Khan \& Takahashi, 2006).

\section{Results and Discussion}

The simulation graph below is drawn from the following matrices:

$$
\text { The initial matrix: }\left(\begin{array}{ll}
0.45 & 0.55 \\
0.55 & 0.45
\end{array}\right)
$$

The converging matrix is:

$$
\left(\begin{array}{ll}
0 & 1 \\
1 & 0
\end{array}\right)
$$

Figure 1 shows the change in the probability distribution after each conflict interaction. After six conflict interaction it reached to equilibrium distribution ( 0 and 1$)$.

Firstly, this model explains Hume's convention theory. It 

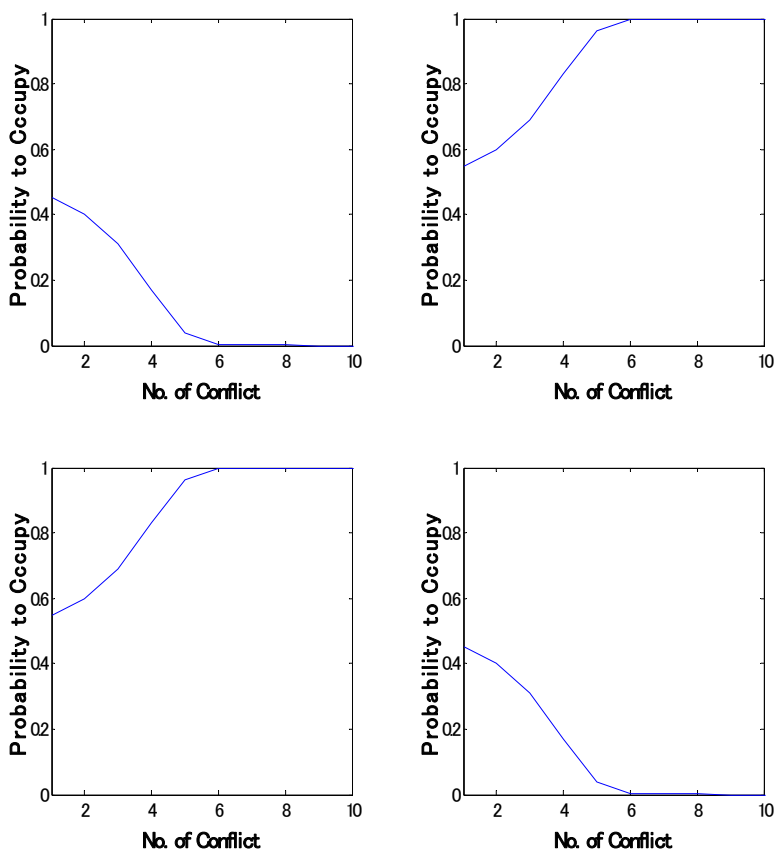

Figure 1.

The simulation results of the four elements of the $2 \times 2$ matrix.

effectively demonstrates how the convergence would occur visually.

The conclusion is that the matrix reaches the equilibrium whereby $100 \%$ of the members of a society would agree a system of actions spontaneously:

"And justice establishes itself by a kind of convention or agreement; that is, by a sense of interest, suppos'd to be common to all, and where every single act is perform'd in expectation that others are to perform the like. Without such a convention, no one wou'd ever have dream'd, that there was such a virtue as justice, or have been induc'd to conform his actions to it” (Hume, 2000: 3.2.2.).

Therefore, certain cooperation between members could be possible, but only informally and with some conditions. He posits that: "and this motive (a regard to interest), on the first formation of society, is sufficiently strong and forcible. But when society has become numerous, and has encreas'd to a tribe or nation, this interest is more remote; nor do men so readily perceive, that disorder and confusion follow upon every breach of these rules, as in a more narrow and contracted society" (ibid.). Small society is the first condition for making informal cooperation possible.

"And so far am I from thinking with some philosophers that men are utterly incapable of society without government, that I assert the first rudiments of government to arise from quarrels, not among men of the same society, but among those of different societies” (ibid. 3.2.8.). Being without an outside enemy is, therefore, the second condition for maintaining informal society. However, usually our society has enemies outside itself. That should be a necessary condition for making formal government. Hume's convention could be established with these qualifications and this model explains it effectively.

Secondly, this model also explains the actual phenomena of the segregation. There have been some modifications of the Schelling model and some alternatives considered (ex. Bruch \&
Mare, 2005). Previously, segregation between white and black in America was investigated. This segregation comprised two attributes, one of which (residency) is changeable and the other ("race") is not. The authors represent that changeable as a column and unchangeable as a row. Conflict occurs in the same column between different rows. In this case, conflicting elements would change their column, consequently conflicts would diminish and then disappear.

Recently, however, the segregation between those two "races" has been said to be in decline for several decades. Instead language, education and immigration status (Hispanic \& Asian) are factors increasingly leading to segregation, especially segregation between income levels (Massey \& Denton, 1987, Miller \& Quigley, 1990, Bayer et al., 2002). People can see many "islands" in a city, which consist of only the rich or the poor. The phenomenon of the "Gated Community" has become widespread in suburban areas illustrating exactly $100 \%$ segregation. According to Hume $100 \%$ agreement within a small group without outside enemies would easily occur, as explained with the segregation model.

In the population game and Koshmanenko's conflict model, the matrix reaches equilibrium; but the process of how it arrives at the results is unknown. What is certain is that it anyhow reaches equilibrium in the population game, and it can also be proved by Koshmanenko that it does so. This model can generalize Koshmanenko's model and explain the process of arriving at the equilibrium.

\section{Conclusion}

The main strong point of this study is that its modeling allows for an explanation of how segregation emerges, how people arrive at a convention and how an institution is established. An institution can be defined as the equilibrium reached through the interaction of conflicting groups. Here it is applied to conflict between "races" but can be extended to the analysis of other factors, for example, language, education level and the difference of income among others.

\section{REFERENCES}

Aoki, M. (2000). What are institutions and how should we approach them? http://www.dse.de/ef/instn/aoki.htm

Aoki, M. (2001). Toward a comparative institutional analysis. Cambridge, MA: The MIT Press.

Bayer, P. et al. (2004). What drives racial segregation? New evidence using census microdata. Journal of Urban Economics, 56, 514-535. http://dx.doi.org/10.1016/j.jue.2004.06.002

Bruch, E., \& Mare, R. D. (2005). Neighborhood choice and neighborhood change. Online Working Paper Series, Los Angeles: University of California.

Gintis, H. (2000). Game theory evolving a problem-centered introduction to modeling strategic integration. Princeton, NJ: Princeton University Press.

Hobbes, T. (1968) Leviathan, or the matter, forme, \& power of a common wealth ecclesiasticall and civill. London: Penguin Books.

Hume, D. (2000). A treatise on human nature. Oxford: Oxford University Press.

Kandori, M. et al. (1993) Learning, mutation, and long run equilibria in games. Econometrica, 61, 29-56. http://dx.doi.org/10.2307/2951777

Khan, M. S., \& Takahashi, K. (2006). Mathematical model of conflict with non-annihilating multi-opponent. Journal of Interdisciplinary Mathematics, 9, 459-473.

Koshmanenko, V. (2003). Theorem on conflicts for a pair of stochastic 


\section{S. MD. M. KHAN, K. I. TAKAHASHI}

vectors. Ukrainian Mathematical Journal, 55, 671-678.

http://dx.doi.org/10.1023/B:UKMA.0000010167.63115.37

Koshmanenko, V. (2004) . Theorem of conflicts for a pair of probability measures. Mathematical Methods of Operations Research, 59, 303-313. http://dx.doi.org/10.1007/s001860300330

Massey, D. S., \& Denton, N. A. (1987). Trends in the residential segregation of blacks, Hispanics, and Asians: 1970-1980. American Sociological Review, 52, 802-825. http://dx.doi.org/10.2307/2095836

Matsui, A. (1996). On cultural evolution: Social norms, rational behavior, and evolutionary game theory. Journal of The Japanese and International Economies, 10, 262-294.

http://dx.doi.org/10.1006/jjie.1996.0015

Miller, V. P., \& Quigley, J. M. (1990). Segregation by racial and demographic group: Evidence from the San Francisco Bay Area.
Urban Studies, 27, 3-21.

http://dx.doi.org/10.1080/00420989020080011

Morrow, J. D. (1994). Game theory for political scientists. Princeton, NJ: Princeton University Press.

Schelling, T. C. (1969). Models of segregation. American Economic Review, Papers and Proceedings, 59, 488-493.

Smith, A. (1976). The theory of moral sentiments. Oxford: Oxford University Press.

Young, P. H. (1993). The evolution of conventions. Econometrica, 61, 57-84. http://dx.doi.org/10.2307/2951778

Young, P. H. (1998). Individual strategy and social structure. Princeton, NJ: Princeton University Press.

Weibull, J. W. (1995). Evolutionary game theory. Cambridge, MA: The MIT Press. 